\title{
Unusual Sculpting of Dipeptide Particles by Ultrasound Induces Gelation
}

\author{
David Bardelang, Franck Camerel, James C. Margeson, Donald M. Leek, \\ Marc Schmutz, Md. Badruz Zaman, Kui Yu, Dmitriy V. Soldatov, Raymond Ziessel, \\ Christopher I. Ratcliffe, John A. Ripmeester.
}

Scheme S1. Peptide coupling between FmocLeuOH and H-LeuOBn tosylate.

Figure S1. Gelation of alkane series from n-pentane to n-hexadecane (left to right).

Figure S2. SEM micrograph of dipeptide 1 particles dispersed for several days in hexane.

Figure S3. 2D-ROESY experiment performed on a $\mathrm{d}_{14}$-hexane solution of dipeptide 1 $(5 \mathrm{mg}, 15 \mathrm{mM})$ at $60^{\circ} \mathrm{C}$.

Figure S4. Hyperchem rendering of the molecular structure of gelator $\mathbf{1}$ in its conformation as deduced from the 2D ROESY spectrum highlighting the strong correlation between the protons circled in red.

Figure S5. Solid state CP-MAS ${ }^{13} \mathrm{C}$ NMR spectra of (a) the precipitate, (b) the xerogel and (c) a nonane gel prepared with dipeptide $\mathbf{1}$.

Figure S6. (a) X-ray diffraction patterns of the as-synthesized material and of a xerogel obtained after $60 \mathrm{~s}$ of sonication; (b) DSC traces of the as-synthesized material and xerogels as a function of the applied sonication time in nhexane. 


\section{Preparation of dipeptide 1.}

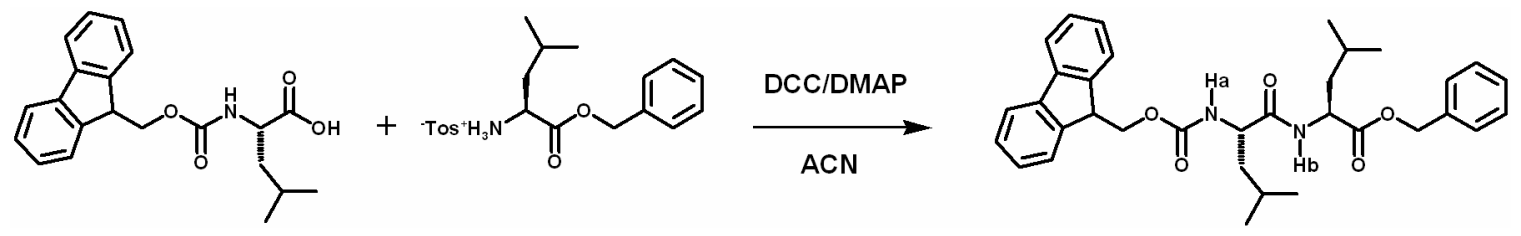

Scheme S1. Peptide coupling between FmocLeuOH and H-LeuOBn tosylate.

FmocLeuOH (12.57 g, $35.6 \mathrm{mmol})$ and H-LeuOBn tosylate (14 g, $20 \mathrm{mmol}$ amine) both from Novabiochem were introduced together with dicyclohexylcarbodiimide (DCC, 8.07 $\mathrm{g}, 39.1 \mathrm{mmol}$ from Aldrich) and dimethylaminopyridine (DMAP, 1.74g, $14.2 \mathrm{mmol}$ from Aldrich) in a $500 \mathrm{~mL}$ flask before placing under nitrogen and adding $250 \mathrm{~mL}$ of acetonitrile. The reaction was stirred at room temperature and followed by TLC before stopping it after 6 hours by filtering the solution to remove the white precipitate of dicyclohexylurea. The solvent was then removed under reduced pressure giving a yellowish very sticky oil that was purified by flash chromatography using a gradient hexane/ethyl acetate (from 495/5 to 3/1) as the eluant affording $8.3 \mathrm{~g}$ of dipeptide $\mathbf{1}$ as a white solid (42\% yield). $M=556.70$. m.p. $94-95^{\circ} \mathrm{C}$. ${ }^{1} \mathrm{H}$ NMR $\left(400 \mathrm{MHz}, \mathrm{CDCl}_{3}, 298 \mathrm{~K}\right)$ : $\delta=7.77\left(\mathrm{~d}, J=7.6 \mathrm{~Hz}, 2 \mathrm{H},-\mathrm{OCH}_{2} \mathrm{CH}\left(\mathrm{C}_{6} H_{4}\right)_{2}\right), 7.59(\mathrm{~d}, J=7.6 \mathrm{~Hz}, 2 \mathrm{H}$, $\left.\mathrm{OCH}_{2} \mathrm{CH}\left(\mathrm{C}_{6} \mathrm{H}_{4}\right)_{2}\right), 7.43-7.30\left(\mathrm{~m}, 9 \mathrm{H},-\mathrm{OCH}_{2} \mathrm{CH}\left(\mathrm{C}_{6} H_{4}\right)_{2}\right.$ and $\left.-\mathrm{CH}_{2} \mathrm{C}_{6} H_{5}\right), 6.32(\mathrm{~d}, J=7.9$ $\mathrm{Hz}, 1 \mathrm{H}, \mathrm{FmocNHCHCONH-),} 5.24$ (d, $J=8.4 \mathrm{~Hz}, 1 \mathrm{H}, \mathrm{FmocNHCH}-), 5.18$ (d, $J=12.3$ $\left.\mathrm{Hz}, 1 \mathrm{H},-\mathrm{CH}_{2} \mathrm{C}_{6} \mathrm{H}_{5}\right), 5.14\left(\mathrm{~d}, J=12.3 \mathrm{~Hz}, 1 \mathrm{H},-\mathrm{CH}_{2} \mathrm{C}_{6} \mathrm{H}_{5}\right), 4.63-4.69$ (m, 2H, -NHCHCO), 4.35-4.44 (m, 2H, $\left.-\mathrm{OCH}_{2} \mathrm{CH}\left(\mathrm{C}_{6} \mathrm{H}_{4}\right)_{2}\right), 4.22\left(\mathrm{t}, J=6.9 \mathrm{~Hz}, 1 \mathrm{H},-\mathrm{OCH}_{2} \mathrm{CH}\left(\mathrm{C}_{6} \mathrm{H}_{4}\right)_{2}\right), 1.51-$ $1.70\left(\mathrm{~m}, 6 \mathrm{H},\left[-\mathrm{CH}_{2} \mathrm{CH}\left(\mathrm{CH}_{3}\right)_{2}\right]_{2}\right), 0.93\left(\mathrm{~d}, J=5.5 \mathrm{~Hz}, 6 \mathrm{H},-\mathrm{CH}_{2} \mathrm{CH}\left(\mathrm{CH}_{3}\right)_{2}\right), 0.89(\mathrm{dd}, J=$ $\left.6.03 .7 \mathrm{~Hz}, 6 \mathrm{H},-\mathrm{CH}_{2} \mathrm{CH}\left(\mathrm{CH}_{3}\right)_{2}\right)$ ppm. ${ }^{13} \mathrm{C} \mathrm{NMR}\left(400 \mathrm{MHz}, \mathrm{CDCl}_{3}, 298 \mathrm{~K}\right) \delta 172.6$, $172.1,156.4,144.0,143.9,135.5,128.8,128.6,128.4,127.9,127.3,125.2$, 120.2, 67.3, 53.5, 51.1, 47.3, 41.6, 25.0, 24.8, 23.1, 22.9, 22.2, 22.1. IR (KBr) 3680 (w, broad), 3302 (m, broad), 3080 (w, broad), 2922 (w, broad), 2237 (w), 1946 (w), 1775 (s), 1716 (s), 1693 (s), 1648 (s), 1510 (s), 1437 (s), 1376 (s), 1316 (s), 1258 (s), 1225 (s), 936 (m), 870 (m), 795 (w), $750(\mathrm{w}), 730$ (s), 693 (s), 628 (s), 581 (s). UV-vis $\left(\mathrm{CHCl}_{3}\right) \lambda_{\max }(\varepsilon) 267$ (182000), 290 (65000), $301 \mathrm{~nm}$ (70000 M $\left.\mathrm{M}^{-1} . \mathrm{cm}^{-1}\right)$. HPLC/MS m/z 557.7 (96\%). MS $(\mathrm{ESI}+, 70 \mathrm{eV}): \mathrm{m} / z(\%) 557.4(100)\left[M^{+}+\mathrm{H}\right], 574.4(40)\left[M^{+}+\mathrm{NH}_{4}\right], 579.3(20)\left[M^{+}+\mathrm{Na}\right]$. 
Alkanes were from Aldrich at the highest purity available, kerosene from Fluka Chemika, olive oil from local store and parafin oil from BDH inc. Toronto (d 0.83-0.86).

NMR. All the solution NMR spectra were recorded using a Bruker DRX-400 spectrometer, operating at $400.13 \mathrm{MHz}$ for ${ }^{1} \mathrm{H}$ and $100.62 \mathrm{MHz}$ for ${ }^{13} \mathrm{C}$. 2D spectra were recorded using an inverse-detected gradient probe. ${ }^{13} \mathrm{C}$ spectra were recorded using a directed-detected broadband probe. Standard Bruker pulse sequences were used for all experiments.

IR. FT-IR spectra were recorded on gels with a closed IR cell equipped with dried $\mathrm{CaF}_{2}$ windows on a Perkin-Elmer "spectrum-one" apparatus. For solid samples, the powder was simply deposited between two dried $\mathrm{KBr}$ pellets.

HPLC/MS. HPLC/MS analysis was performed with a Waters Alliance 2795 liquid chromatograph equipped with a Waters 996 PDA diode array detector and connected to a Micromass ZQ2000 mass spectrometer equipped with pneumatically-assisted electrospray ionization source, operating in positive mode. The Waters SunFire C18 $(2.1 \times 100 \mathrm{~mm}, 3.5 \mu \mathrm{m})$ column was used. HPLC analysis was performed with gradient (10$95 \%$ over $10 \mathrm{~min}$.) elution of acetonitrile/water both with $0.1 \%$ formic acid. The flow rate was $0.2 \mathrm{ml} / \mathrm{min}$. The eluent was directed to the diode array detector and then to the mass spectrometer. The source temperature was set at $80^{\circ} \mathrm{C}$, desolvation gas temperature was set at $200^{\circ} \mathrm{C}$, and an electrospray capillary was set at $3.5 \mathrm{kV}$ with a cone voltage set at $10 \mathrm{~V}$. The data were collected in centroid scan mode with range 150-1000 amu.

Melting point. Melting points were measured using a Mel-Temp apparatus at a heating rate of $1^{\circ} \mathrm{C}$ per minute.

Scanning Electron Microscopy. Images were acquired on a Hitachi S-4800 Cold Field Emission Scanning Electron Microscope (SEM). This instrument was fitted with two secondary detectors and images were acquired using a mixed image of the two signals at a working distance of $8 \mathrm{~mm}$. An Oxford Inca Energy Dispersive Spectrometer (EDS) was 
also attached to the instrument to provide elemental analysis of the image area. Images were acquired at a beam energy of $2 \mathrm{keV}$ and a current of $5 \mu \mathrm{A}$. A series of magnifications of regions of interest was imaged to show the grain size and micromorphology of the studied dry materials deposited onto aluminium stubs on adhesive carbon tape.

Freeze Fracture Electron Microscopy. FFEM experiments were performed with a CM 12 Philips microscope on metallic replicas of the gels obtained by the freeze fracture technique.

Powder X-ray diffraction. All diffractograms were recorded on a Bruker D8 Advance diffractometer using a $\mathrm{Cu}_{\mathrm{K} \alpha}$ radiation at $\lambda=1.54056 \AA$. Reflexions were collected from 5 to $60^{\circ}$ with a step width of $0.03^{\circ}$ and a step time of $189 \mathrm{~s}$ at $17^{\circ} \mathrm{C}$.

Differential Scanning Calorimetry. DSC experiments were performed on a TA 2050 analyzer under nitrogen flows of $40 \mathrm{~mL} \cdot \mathrm{min}^{-1}$ for sealed aluminium pans containing around $2.3 \mathrm{mg}$ of dipeptide $\mathbf{1}$ as bulk material and $1.6 \mathrm{mg}$ for the solids prepared using sonication and using a heating rate of $5^{\circ} \mathrm{C} \cdot \mathrm{min}^{-1}$.

Solid State NMR. Solid state ${ }^{13} \mathrm{C} \mathrm{CP/MAS} \mathrm{NMR} \mathrm{spectra} \mathrm{were} \mathrm{obtained} \mathrm{at} 75.43 \mathrm{MHz}$ on a Bruker AMX300 spectrometer, with a Doty Scientific Inc. $5 \mathrm{~mm}$ probe using silicon nitride rotors. All three samples were run with a ${ }^{1} \mathrm{H} 90^{\circ}$ pulse length of $4.7 \mu \mathrm{s}$, a CP time of $1 \mathrm{~ms}$, and $2 \mathrm{~s}$ recycle times. For spectra without $\mathrm{CP}$ a simple one pulse sequence with ${ }^{1} \mathrm{H}$ decoupling (HPDEC) was used, with a ${ }^{13} \mathrm{C} 90^{\circ}$ pulse length of $5.0 \mu$ s and 8 s recycle times. The precipitate and xerogel were spun at $7 \mathrm{kHz}$ and the gel at $3 \mathrm{kHz}$. Chemical shifts were referenced to TMS via external hexamethylbenzene.

Computational details. A 3D model was generated with the Hyperchem 7.51 molecular modeling software using the AMBER force field. The conformation shown in the model is consistent with the NMR results obtained with the compound dissolved in $\mathrm{d}_{14}$-hexane. 
Preparation of xerogels for PXRD, CP-MAS ${ }^{13}$ C NMR, IR and DSC. $250 \mathrm{mg}$ of gelator were introduced into a vial before addition of $17.5 \mathrm{~mL}$ of hexane $(5 \mathrm{mg} / 350 \mu \mathrm{L}$ concentration). The vial was placed in the sonication bath for around 3 minutes. Xerogels were obtained by slow evaporation of the solvent at room temperature. For DSC, gel or thick liquid samples $(26 \mathrm{mM})$ prepared with various sonication times were simply allowed to dry in air overnight before analyses.

Preparation of the gel for CP-MAS ${ }^{\mathbf{1 3}} \mathbf{C}$ NMR. A nonane gel $(5 \mathrm{mg}$ of $\mathbf{1}$ in $350 \mu \mathrm{L}$ solvent followed by 2 minutes sonication) was prepared. Nonane was selected for its higher boiling point (compared to that of hexane) in order to prevent solvent evaporation during the experiments.

It was observed that heating the solution above the compound solubility point (around $90^{\circ} \mathrm{C}$ for 5 minutes) and cooling the solution to room temperature was not followed by gel formation; this is a clear indication of a non-classical gelator (see Table S1).

Table S1. Solvents tested for gelation with compound 1 by classical heating/cooling cycles.

(S: solution, I: insoluble).

\begin{tabular}{|c|c|c|c|c|c|c|c|c|}
\hline Entry & Solvent & 1 & Entry & Solvent & 1 & Entry & Solvent & 1 \\
\hline 01 & Water & I & 11 & $\mathrm{CH}_{3} \mathrm{NO}_{2}$ & $\mathrm{~S}$ & 21 & DMF & $\mathrm{S}$ \\
\hline 02 & Methanol & $\mathrm{S}$ & 12 & Acetonitrile & $\mathrm{S}$ & 22 & DMSO & $\mathrm{S}$ \\
\hline 03 & Ethanol & $\mathrm{S}$ & 13 & Pyridine & $\mathrm{S}$ & 23 & Ethylacetate & $S$ \\
\hline 04 & 2-Propanol & $\mathrm{S}$ & 14 & TEA & $\mathrm{S}$ & 24 & Toluene & $S$ \\
\hline 05 & 1-Octanol & $\mathrm{S}$ & 15 & 1-Me-imidazole & $\mathrm{S}$ & 25 & Chlorobenze & $S$ \\
\hline 06 & Glycerol & $\mathbf{I}$ & 16 & Diethyl ether & $\mathrm{S}$ & 26 & Nitrobenze & $\mathrm{S}$ \\
\hline 07 & Butyl- $\mathrm{NH}_{2}$ & $\mathrm{~S}$ & 17 & 1,4-Dioxane & $\mathrm{S}$ & 27 & n-Hexane & I \\
\hline 08 & Acetone & $\mathrm{S}$ & 18 & THF & $\mathrm{S}$ & 28 & n-Hexadecane & $\mathbf{I}$ \\
\hline 09 & $\mathrm{CH}_{2} \mathrm{Cl}_{2}$ & $\mathrm{~S}$ & 19 & Thiophene & $\mathrm{S}$ & 29 & Cyclohexane & I \\
\hline 10 & $\mathrm{CHCl}_{3}$ & $\mathrm{~S}$ & 20 & $\mathrm{CS}_{2}$ & $\mathrm{~S}$ & 30 & TEOS & I \\
\hline
\end{tabular}


Ultrasound gelation tests. All gelation tests were performed using $5 \mathrm{mg}$ of dipeptide dispersed in $350 \mu \mathrm{L}$ of solvent except for the water/methanol system for which $400 \mu \mathrm{L}$ of solvent mixture was used. The capped vials were introduced into a sonication bath and submitted to ultrasound for various exposure times. Ultrasonic bath parameters: VWR international Ltd, Mississauga, Canada, $40 \mathrm{~Hz}$ industrial stacked transducers. Capacity, $2.8 \mathrm{~L}$, tank dimensions, $24 \times 14 \times 10.2 \mathrm{~cm}$, frequency $40.0 \mathrm{kHz}$, power $0.28 \mathrm{~W} . \mathrm{cm}^{-2}$. The gelation was simply confirmed by inverting the vial and checking that the immobilized solution did not flow.

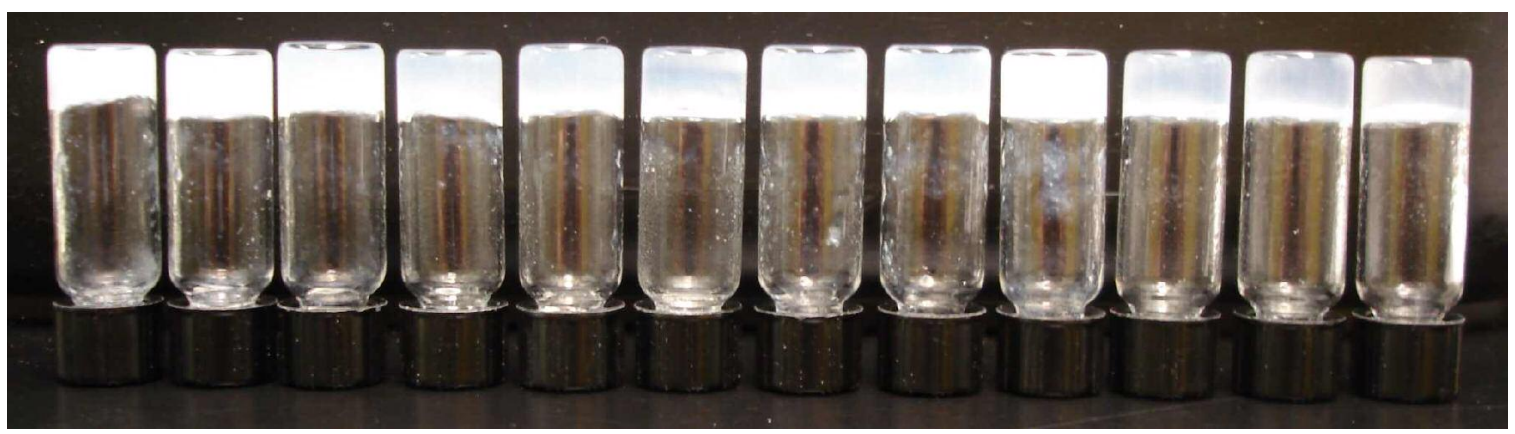

Figure S1. Gelation test of an alkane series from n-pentane to n-hexadecane (left to right) performed at $20^{\circ} \mathrm{C}$.

A linear increase of $7^{\circ} \mathrm{C}$ can be measured in the bath or directly in the sample during gel formation after 10 minutes of ultrasound exposure. These results confirm the limited effect of the temperature in the ultrasonic gelation process since gelation was observed in most cases after only 1 minute of sonication. 


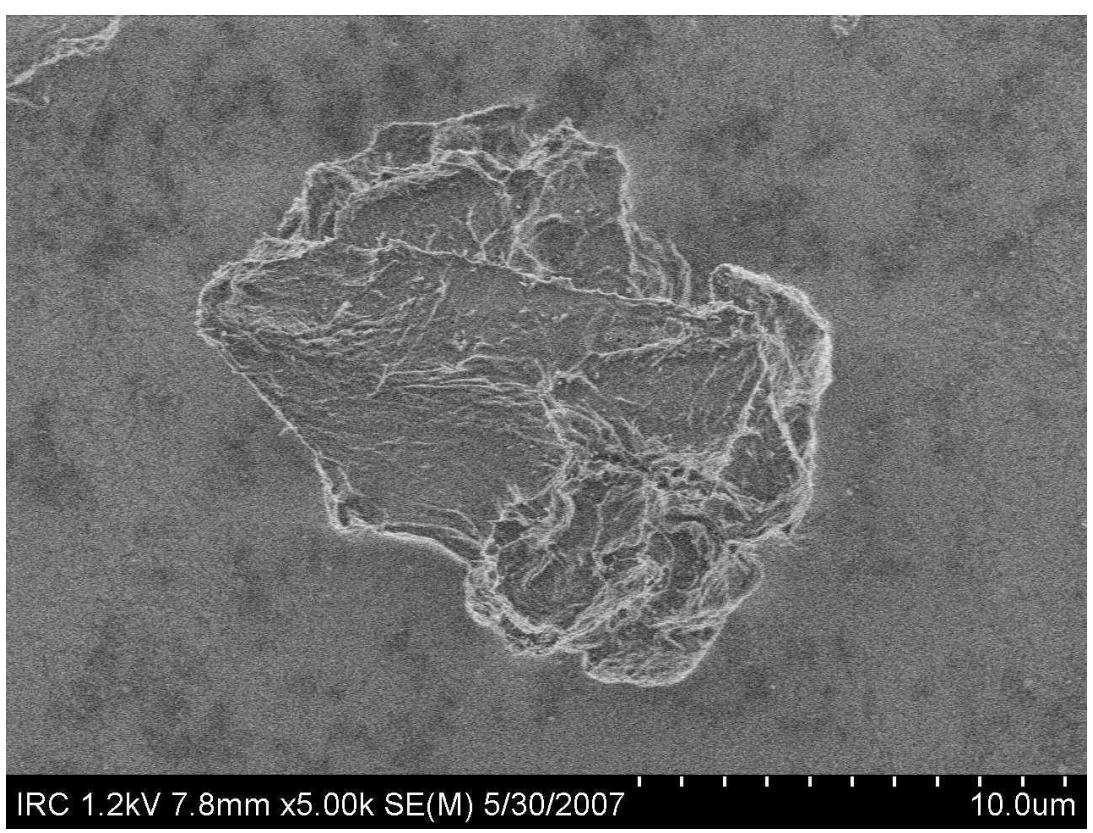

Figure S2. SEM micrograph of dipeptide 1 particles dispersed for several days in hexane. 


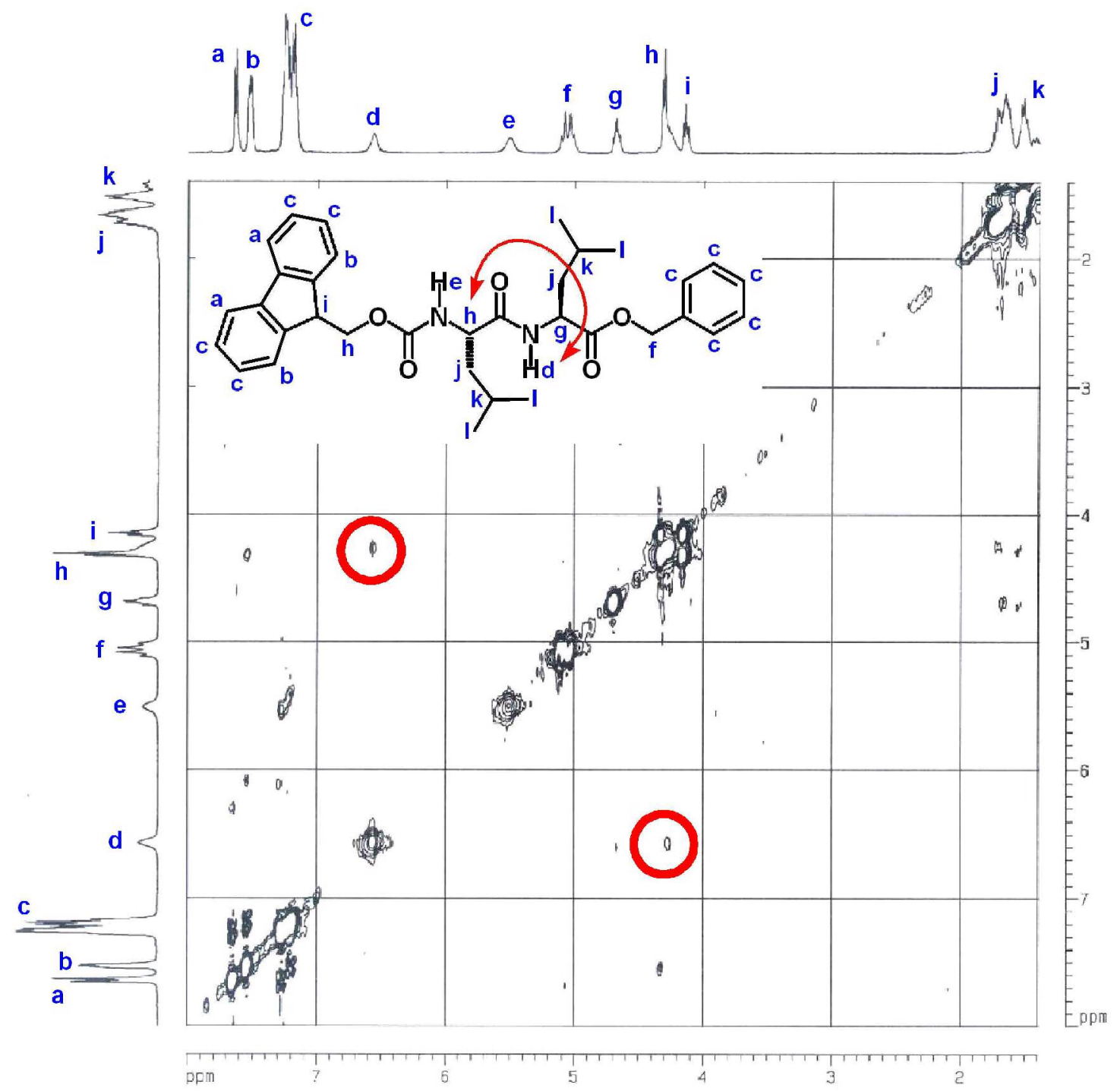

Figure S3. 2D-ROESY experiment performed on a $\mathrm{d}_{14}$-hexane solution of dipeptide 1 $\left(5 \mathrm{mg}, 15 \mathrm{mM}\right.$ ) at $60^{\circ} \mathrm{C}$. 


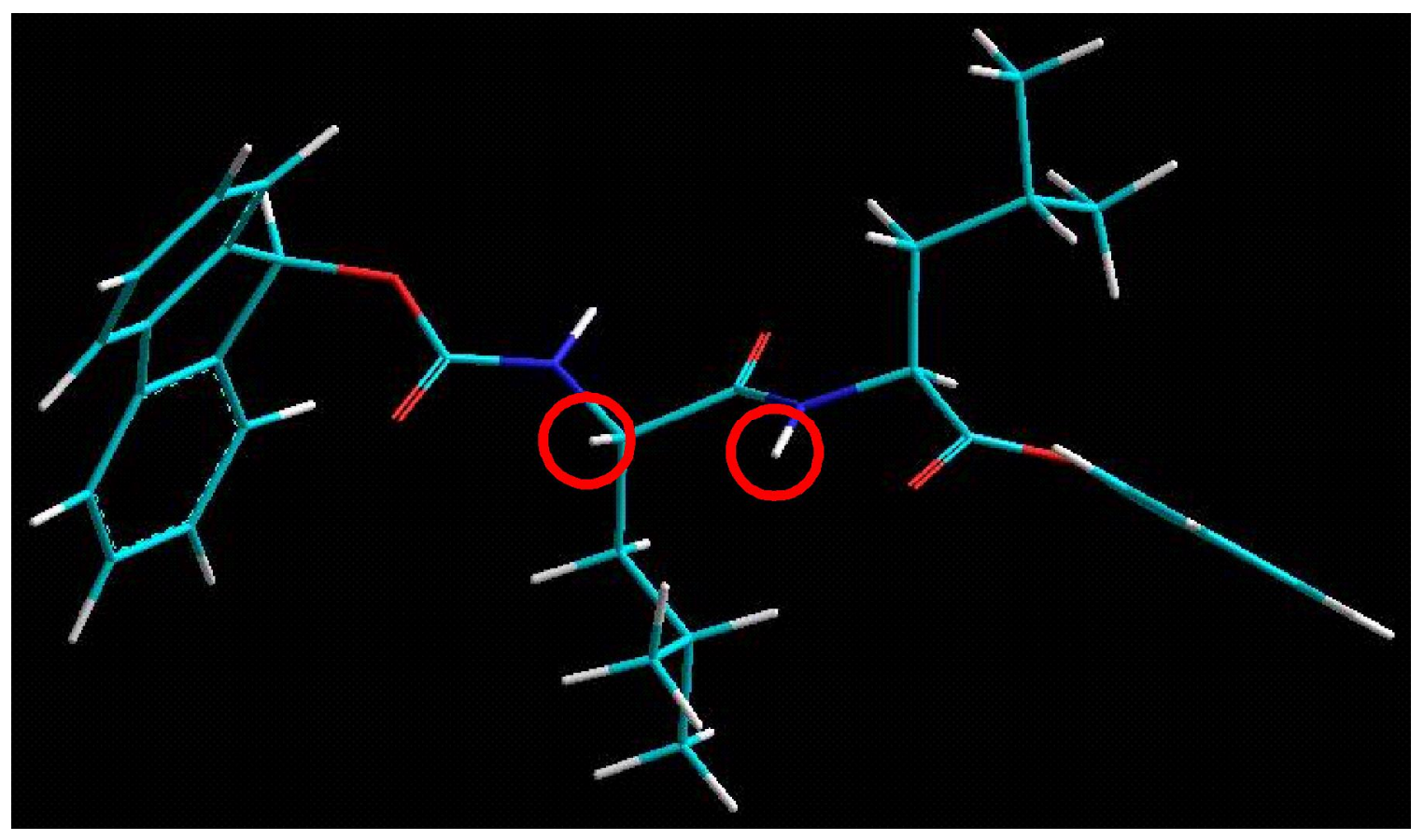

Figure S4. Hyperchem rendering of the molecular structure of gelator 1 in its conformation as deduced from the 2D ROESY spectrum highlighting the strong correlation between the protons circled in red. 


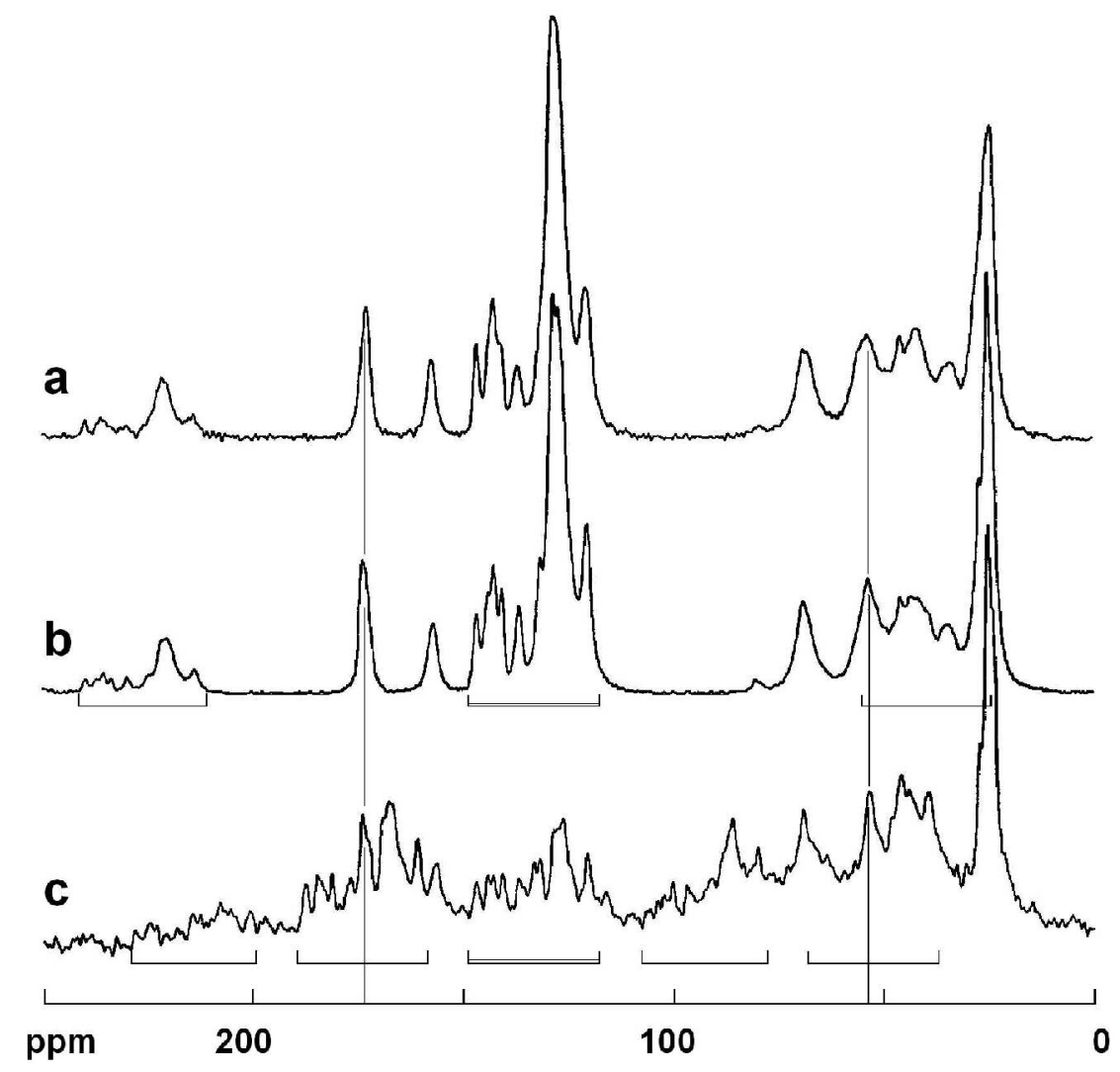

Figure S5. Solid state CP-MAS ${ }^{13} \mathrm{C}$ NMR spectra of (a) the precipitate (spin rate $=7$ $\mathrm{kHz})$, (b) the xerogel (7 kHz) and (c) a nonane gel prepared with dipeptide $1(3 \mathrm{kHz})$.

The observed peaks for the carbonyl and $\mathrm{C} \alpha$ carbon atoms at 173 and $53 \mathrm{ppm}$ respectively, indicated by the vertical lines in Fig. S5, are attributed to Leucine amino acids in $\beta$-sheet conformations as has already been reported for analogous compounds (see BioMagResBank, www.bmrb.wisc.edu), ${ }^{\mathrm{i}, \mathrm{ii}}$ MAS on the gel ${ }^{\mathrm{iii}}$ was carried out at the slower spin rate of $3 \mathrm{kHz}$ in order to try to preserve the gel state: While this still resulted in expulsion of a substantial fraction of the liquid from the gel, after the NMR experiment the compacted material still had a very soft gel texture. Furthermore, a non-CP spectrum of the gel with decoupling, which should show all carbons, was dominated by the spectrum of the liquid nonane which was still present in the gel. The CP experiment shows only solid-like material where dipolar coupling between ${ }^{1} \mathrm{H}$ and ${ }^{13} \mathrm{C}$ can occur, and the gel spectrum displays essentially the same signals as the precipitate and xerogel. The isotropic shift lines for the aromatic carbons are indicated by the double-lined bracket and 
the regions of the corresponding spinning side bands (ssbs) are indictaed by the singlelined brackets. The ssbs in the gel spectrum at $3 \mathrm{kHz}$ contribute minimal intensity in the aliphatic region.
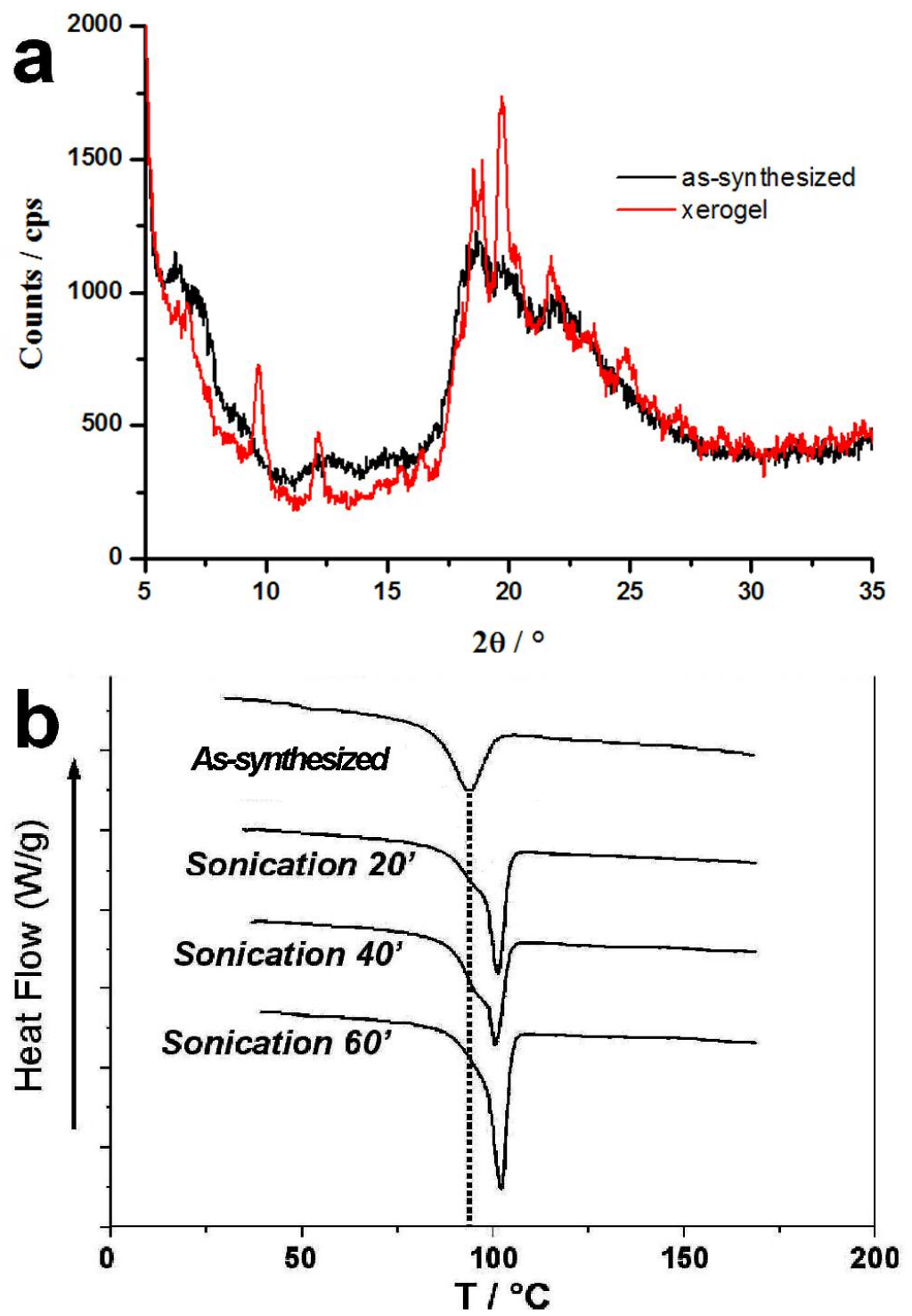

Figure S6. (a) X-ray diffraction patterns of the as-synthesized material and of a xerogel obtained after $60 \mathrm{~s}$ of sonication; (b) DSC traces of the as-synthesized material and xerogels as a function of the applied sonication time in n-hexane. 
${ }^{\mathrm{i}}$ U. Baxa, R. B. Wickner, A. C. Steven, D. E. Anderson, L. N. Marekov, W.-M. Yau, R. Tycko, Biochemistry, 2007, 46, 13149-13162.

${ }^{i i}$ K. H. Lim, T. N. Nguyen, S. M. Damo, T. Mazur, H. L. Ball, S. B. Prusiner, A. Pines, D. E. Wemmer, Solid State NMR, 2006, 29, 183-190.

iii The inherently smaller amount of dipeptide in the gel (around $2 \mathrm{mg}$ instead of $150 \mathrm{mg}$ for the precipitate or xerogel) required accumulation of 100000 scans. Nonane was also selected in order to reduce solvent loss during the long acquisition time. 